\title{
Parental monitoring: a way to decrease substance use among Swiss adolescents?
}

\author{
Lionel Tornay • Pierre-André Michaud • \\ Gerhard Gmel • Michael L. Wilson • André Berchtold • \\ Joan-Carles Surís
}

Received: 12 November 2012 / Accepted: 27 April 2013 / Published online: 10 May 2013

(C) Springer-Verlag Berlin Heidelberg 2013

\begin{abstract}
The objective of this research was to determine whether the level of parental monitoring is associated with substance use among adolescents in Switzerland, and to assess whether this effect remains when these adolescents have consuming peers. For this purpose, we used a nationally representative sample from the Swiss participation in the 2007 European School Project on Alcohol and Other Drugs survey, which included 7,611 adolescents in public schools (8th-10th grades). Four levels of parental control were created and four substances (tobacco, alcohol, cannabis, and ecstasy) were analyzed. All significant variables at the bivariate level were included in the multivariate analysis. Most adolescents had a high level of parental monitoring and that was associated with younger age, females, high socioeconomic status, intact family structure, and satisfactory relationships with mother, father, and peers. Overall, substance use decreased as parental monitoring increased and high parental monitoring decreased as having consuming peers increased. Results remained essentially the same when the variable "having consuming peers" was added to the analysis. Conclusion: parental monitoring is associated to positive effects on adolescent substance use with a reduction of consumption and a lower probability of having
\end{abstract}

\footnotetext{
L. Tornay · P.-A. Michaud · M. L. Wilson • A. Berchtold • J.-C. Surís

Institute of Social and Preventive Medicine, Lausanne University

Hospital, Lausanne, Switzerland

G. Gmel

Alcohol Treatment Center, Lausanne University Hospital, Lausanne, Switzerland

J.-C. Surís $(\bowtie)$

Research Group on Adolescent Health, Institute of Social and Preventive Medicine, Route de la corniche 10,

1010 Lausanne, Switzerland

e-mail: joan-carles.suris@chuv.ch
}

consuming peers, which seems to protect adolescents against potentially negative peer influence. Encouraging parents to monitor their adolescents' activities and friendships by establishing rules about what is allowed or not is a way to limit the negative influence of consuming peers on adolescent substance use.

Keywords Adolescence $\cdot$ Substance use $\cdot$ Parents $\cdot$ Peers

\section{Introduction}

Substance use is associated with a number of health and social problems. Tobacco, cannabis, and alcohol misuse are linked to physical and psychosocial ill health, unsafe sexual practices, and crime $[8,16,18,23,25]$. Furthermore, the care and excess morbidity associated with substance use are linked to increased costs for healthcare and legal systems [21, 24].

Most experimentation with substances begins during adolescence [5, 31, 33]. Data from the Health Behavior in School-aged Children (HBSC) international report show gender differences concerning current substance use among 15 -year-olds, with higher consumption among boys. In Switzerland, $15 \%$ of 15 -year-olds (boys and girls) are weekly smokers, $29 \%$ of boys and $18 \%$ of girls have been drunk at least twice during their lifetime, and $13 \%$ of boys and $11 \%$ of girls have used cannabis in the last 30 days; compared to the HBSC average rates, 15-year-olds living in Switzerland show lower rates of smoking and alcohol misuse but higher rates of cannabis consumption [10]. Moreover, there has been a significant increase in ecstasy use among adolescents in Switzerland between 1993 and 2002 [20].

Several factors are associated with increased substance use in adolescence, among which is the relationship that adolescents have with their parents and peers. Previous 
research has shown that spending time with friends who use substances greatly increases the risk of consumption $[12,13$, $26,30]$. Research has also shown that authoritative [6] parenting and high parent involvement, support, or monitoring [28] are linked with lower levels of substance use by adolescents and have a protective effect both on the consumption initiation and continuation $[3,7,9,22]$.

Earlier studies concerning adolescent substance use have examined parental monitoring controlling for peers' use, but have found divergent results. For example, in their longitudinal study on adolescent substance use, Steinberg et al. [29] showed that the influence of peer groups on substance use transitions does not vary as a function of parental monitoring. Alternatively, Kiesner et al. [17] showed that the relationship between substance co-use with friends and individual substance use is stronger when the level of parental monitoring is low. Dishion et al. [11] suggested that family management and peer contexts both combine to account for individual differences in late adolescent adjustment and that the deterioration of the parent-peer socialization environment is bidirectional. As a result, they also suggested that deviant peer involvement may have a disruptive effect on family management. However, Galambos et al. [14] established that having deviant peers was a risk factor for engaging in externalizing behaviors such as substance use, but that parents may play a critical role in diminishing that risk. Different studies $[1,2,15]$ showed furthermore that several family variables such as parental monitoring or attachment to parents have significant and direct influences on adolescent drug use independently from any peer influence, but that this effect is relatively small.

Other authors looked at the combined influences of parents and peers on adolescent substance use. Their work suggests that both peers and parents are important in influencing substance use during adolescence. Wood et al. [32] and Barnes et al. [3] support that parental influence provides a buffering effect against peers' influence on alcohol involvement. The same result was found by Marshall and Chassin [19] in their longitudinal study concerning peer influence on adolescent alcohol use, but only for girls. They showed that for girls, parenting behavior could serve as a protective factor to resist peer group pressure, but that, for boys higher levels of parental support exacerbated the association between consuming peers and alcohol use. However, these studies have been carried out in North America and most of them are based on relatively small nonrepresentative samples. To the best of our knowledge, few studies have been undertaken in Europe and based on nationally representative samples.

The goal of our research is to examine whether the level of parental monitoring is associated with substance use among Swiss adolescents and to assess whether this effect remains when these adolescents have consuming peers. We hypothesize that parental monitoring will decrease adolescents' substance use, even in the presence of consuming peers.

\section{Methods}

Data were drawn from the Swiss participation in the 2007 European School Project on Alcohol and Other Drugs (ESPAD) survey. ESPAD is a European study carried out every 4 years and aiming at investigating the use of alcohol, tobacco, and other drug use and attitudes towards these substances among students aged 15 and 16 years (see www.espad.org for more information). The Swiss part of the survey consisted of a nationally representative sample which included 7,611 adolescents ( $48.8 \%$ boys). The sample was randomly drawn from 418 independent classes issued from 348 public schools (8th, 9th, and 10th grades) around the country. The target population was limited to students who were present in class on the day of data collection. The participation was voluntary and the survey anonymous. Data collection took place through a selfadministrated questionnaire during one classroom period under the same circumstances as a written exam. All analyses take into account the design of the study with adolescents being nested in classrooms.

To measure parental monitoring, we created a scale based on four statements: (1) "My parent(s) set definite rules about what I am allowed to do at home," (2) "My parent(s) set definite rules about what I can do outside the home," (3) "My parent(s) know whom I am with in the evenings," and (4) "My parent(s) know where I am in the evenings." Each one had five possible answers dichotomized into "almost always/often" (coded 1and defined as high monitoring) and "sometimes/seldom/almost never" (coded 0 and defined as low monitoring). We added the four propositions to construct a 0 to 4 scale representing increasing levels of parental monitoring (Cronbach's alpha $=0.62$ ), with each increase in the scale representing one more rule being applied.

We analyzed the use of four substances in the previous 30 days: smoking, alcohol misuse (drunkenness), cannabis use, and ecstasy use. All of them were dichotomized into never and at least once. To measure the number of consuming peers (tobacco smoking, alcohol misuse, cannabis, or ecstasy use) each substance use variable was dichotomized into: "none/a few/some" (coded 0) and "most/all" (coded 1). We also included in the analysis several variables that could play a role in the effect of parental monitoring on adolescent substance use such as: age, gender, self-reported family socioeconomic status, family structure (parents together /other) and satisfaction with the relationship with mother, father, and friends ("very satisfied/satisfied" (coded 1), "indifferent/not so satisfied/not at all satisfied/there is no 
such person" (coded 0$)$ ). To assess family socioeconomic status, we used the following question: "In comparison to other Swiss families, you find your financial situation to be..." with seven possible answers ranging from "very much better off" to "very much less well off" which were then trichotomised into "above average", "average," and "below average."

All analyses were conducted with Stata10 [27]. In the bivariate analysis, we compared each reported level of parental monitoring with the consumption of each substance and the characteristics of the sample. We used Chi square tests for categorical variables and ANOVA for continuous variables. Logistic regressions with results expressed as odds ratio with their corresponding $95 \%$ confidence intervals were performed to highlight a possible influence of parental monitoring on substance use. A second set of regressions also included the influence of peers on consumption as an independent factor. Finally, we also tested for an interaction between parental monitoring and the influence of peers.

\section{Results}

The mean age of the sample was 14.64 years, with $48.8 \%$ being male. The majority of adolescents reported an average socioeconomic status, an intact family structure, and a satisfactory relationship with their mother, father, and peers. Concerning parental monitoring, the more frequently cited statements were knowledge of with whom $(77 \%)$ and where $(77.2 \%)$ the adolescent was in the evening. However, only $52.7 \%$ of parent(s) had definite rules about what the adolescent could do outside the home. The two most strongly associated statements were knowledge of with whom they were and knowledge of where they were (Spearman's rank correlation $=0.6$ ), followed by rules at home and rules outside the home (0.47). The remaining four correlations were all comprised between 0.16 and 0.21 . Concerning substance use, $24.3 \%$ had smoked at least one cigarette, $14.5 \%$ had been drunk, $12.7 \%$ had used cannabis, and $1 \%$ had tried ecstasy at least once during the last 30 days (Table 1). The most significant statement inversely associated with any of the studied substances was knowledge of where they were, with Spearman's correlations ranging from -0.21 (tobacco) to -0.10 (ecstasy).

Table 2 shows the bivariate analysis according to the level of parental monitoring. The majority of adolescents had high level of parental monitoring with more than half of the sample being in levels $3(22.3 \%)$ and $4(34.2 \%)$, while only $7.6 \%$ received low parental monitoring (level 0 ). High parental monitoring was associated with younger age, females, high socioeconomic status, intact family structure, and satisfactory relationships with mother, father, and peers.
Table 1 Characteristics of the sample $(N=7,611)$

\begin{tabular}{ll}
\hline Mean age (years \pm standard error) & $\begin{array}{l}14.64 \pm 0.01 \text { [Range: } 12-18] \\
(\%)\end{array}$ \\
\hline Gender (male) & 48.8 \\
Socioeconomic status & \\
Below average & 5.3 \\
Average & 57.8 \\
Above average & 33.9 \\
Family structure (parents together) & 75.8 \\
Satisfactory relationship with mother & 85.1 \\
Satisfactory relationship with father & 77.5 \\
Satisfactory relationship with peers & 92.0 \\
Smoking in last 30 days & 24.3 \\
Alcohol misuse in last 30 days & 14.5 \\
Cannabis use in last 30 days & 12.7 \\
Ecstasy use in last 30 days & 1.0 \\
Most peers using tobacco & 22.6 \\
Most peers using alcohol & 17.8 \\
Most peers using cannabis & 6.1 \\
Most peers using ecstasy & 0.7 \\
Parental monitoring statements & 63.8 \\
Defined rules at home & 52.7 \\
Defined rules outside the home & 77.0 \\
Knowledge with whom they are & 77.2 \\
Knowledge where they are & \\
\hline
\end{tabular}

Overall, smoking, alcohol misuse, and cannabis or ecstasy use decreased as parental monitoring increased. For example, the prevalence of having been drunk or having used cannabis during the last 30 days was more than 3 times higher if the adolescent had low monitoring than if he/she had high parental monitoring (28.4 vs. $9.1 \%$ for alcohol, 25.3 vs. $7.7 \%$ for cannabis). Moreover, high parental monitoring decreased the prevalence of having consuming peers: an adolescent receiving high parental monitoring reduced approximately in half the prevalence of having tobacco or alcohol consuming peers compared to one with low parental monitoring (17.8 vs. $35.4 \%$ for tobacco, 14 vs. $25.7 \%$ for alcohol).

Table 3 shows the multivariate analysis of the level of parental monitoring on the consumption of each substance with low monitoring as the reference category and controlling for gender, age, self-reported socioeconomic status, family structure, and satisfactory relationship with mother/father/friends. Results revealed that even when controlling for these variables, high parental monitoring decreased the prevalence of all the investigated substances. For alcohol misuse and ecstasy use, the positive effect of parental monitoring was already demonstrated after introducing one single level of monitoring. For smoking and cannabis use, results were slightly different and positive 
Table 2 Bivariate analysis comparing all studied variables according to the level of parental monitoring $(N=7,611)^{\mathrm{a}}$

\begin{tabular}{|c|c|c|c|c|c|c|}
\hline \multirow[b]{2}{*}{$N$} & \multicolumn{6}{|c|}{ Level of parental monitoring ${ }^{b}$} \\
\hline & $\begin{array}{l}0 \\
577(7.6 \%)\end{array}$ & $\begin{array}{l}1 \\
704(9.3 \%)\end{array}$ & $\begin{array}{l}2 \\
1,848(24.3 \%)\end{array}$ & $\begin{array}{l}3 \\
1,725(22.7 \%)\end{array}$ & $\begin{array}{l}4 \\
2,757(36.2 \%)\end{array}$ & $p$ value \\
\hline Mean age (years \pm standard error) & $14.8 \pm 0.05$ & $14.7 \pm 0.04$ & $14.7 \pm 0.02$ & $14.6 \pm 0.02$ & $14.5 \pm 0.02$ & $<0.001$ \\
\hline Gender (male) & $60.0 \%$ & $55.3 \%$ & $50.3 \%$ & $47.4 \%$ & $44.8 \%$ & $<0.001$ \\
\hline SES (below average) & $12.0 \%$ & $10.1 \%$ & $8.3 \%$ & $8.5 \%$ & $7.0 \%$ & 0.001 \\
\hline SES (average) & $59.3 \%$ & $56.7 \%$ & $57.1 \%$ & $58.7 \%$ & $57.6 \%$ & \\
\hline SES (above average) & $28.8 \%$ & $33.2 \%$ & $34.6 \%$ & $32.9 \%$ & $35.4 \%$ & \\
\hline FS (parents together) & $53.0 \%$ & $69.3 \%$ & $74.7 \%$ & $79.2 \%$ & $80.8 \%$ & $<0.001$ \\
\hline SR with mother & $60.5 \%$ & $75.6 \%$ & $84.9 \%$ & $87.7 \%$ & $91.0 \%$ & $<0.001$ \\
\hline SR with father & $51.8 \%$ & $65.9 \%$ & $77.1 \%$ & $80.6 \%$ & $84.2 \%$ & $<0.001$ \\
\hline SR with friends & $74.0 \%$ & $91.6 \%$ & $93.2 \%$ & $93.1 \%$ & $94.3 \%$ & $<0.001$ \\
\hline Smoking & $43.5 \%$ & $38.3 \%$ & $25.4 \%$ & $21.6 \%$ & $17.7 \%$ & $<0.001$ \\
\hline Alcohol misuse & $28.4 \%$ & $20.2 \%$ & $17.3 \%$ & $13.4 \%$ & $9.1 \%$ & $<0.001$ \\
\hline Cannabis use & $25.30 \%$ & $21.3 \%$ & $14.6 \%$ & $11.0 \%$ & $7.7 \%$ & $<0.001$ \\
\hline Ecstasy use & $4.68 \%$ & $1.1 \%$ & $1.1 \%$ & $0.6 \%$ & $0.5 \%$ & $<0.001$ \\
\hline Peers using tobacco & $35.36 \%$ & $32.8 \%$ & $25.7 \%$ & $18.4 \%$ & $17.8 \%$ & $<0.001$ \\
\hline Peers using alcohol & $25.65 \%$ & $27.8 \%$ & $18.5 \%$ & $16.2 \%$ & $14.0 \%$ & $<0.001$ \\
\hline Peers using cannabis & $12.65 \%$ & $9.0 \%$ & $7.1 \%$ & $4.5 \%$ & $4.3 \%$ & $<0.001$ \\
\hline Peers using ecstasy & $2.95 \%$ & $0.9 \%$ & $0.8 \%$ & $0.4 \%$ & $0.4 \%$ & $<0.001$ \\
\hline
\end{tabular}

${ }^{\text {a }}$ Chi-square test was used for categorical variables and ANOVA for continuous variables

${ }^{\mathrm{b}}$ Scale based on the sum of the four statements related to parental rules

SES socioeconomic status, FS family structure, SR satisfactory relationship

effects appeared only when two levels of parental monitoring were reached.

Table 4 shows the same multivariate analysis when peers consuming tobacco, alcohol, cannabis, and ecstasy were added as covariates. Overall, the results remained essentially the same. Finally, we also estimated a model including an interaction term between parental monitoring and consuming peers, but this interaction was nonsignificant and its introduction did not impact significantly the rest of the model (data not shown).

\section{Discussion}

Our results show that parental monitoring is associated with a decreased risk of substance use among adolescents in Switzerland. This finding is consistent with other studies $[4,7,9,22]$. Our results also show that only one single level of parental monitoring has a protective effect on alcohol misuse and ecstasy use, while two are needed for smoking and cannabis use. This effect becomes stronger as the level of parental monitoring increases. Consequently, monitoring

Table 3 Multivariate analyses of the level of parental monitoring (presented as odds ratio with $95 \%$ confidence interval; reference category: no monitoring) on the consumption of each substance

\begin{tabular}{lllll}
\hline & Substances & & \\
\cline { 2 - 5 } Level of parental monitoring $^{\mathrm{b}}$ & Tobacco & Alcohol & Cannabis & Ecstasy \\
\hline Level 1 & $0.91[0.71-1.15]$ & $0.68[0.51-0.89]^{\mathrm{a}}$ & $0.87[0.66-1.14]$ & $0.29[0.12-0.70]^{\mathrm{a}}$ \\
Level 2 & $0.53[0.43-0.66]^{\mathrm{a}}$ & $0.62[0.49-0.78]^{\mathrm{a}}$ & $0.60[0.47-0.77]^{\mathrm{a}}$ & $0.37[0.20-0.71]^{\mathrm{a}}$ \\
Level 3 & $0.46[0.37-0.57]^{\mathrm{a}}$ & $0.49[0.38-0.62]^{\mathrm{a}}$ & $0.46[0.36-0.60]^{\mathrm{a}}$ & $0.22[0.10-0.47]^{\mathrm{a}}$ \\
Level 4 & $0.38[0.31-0.47]^{\mathrm{a}}$ & $0.33[0.26-0.43]^{\mathrm{a}}$ & $0.33[0.26-0.43]^{\mathrm{a}}$ & $0.19[0.10-0.40]^{\mathrm{a}}$ \\
\hline
\end{tabular}

${ }^{\text {a }}$ Statistically significant results

${ }^{\mathrm{b}}$ Controlled for age, gender, socioeconomic status, family structure, satisfactory relationship with mother, satisfactory relationship with father, and satisfactory relationship with friends 
Table 4 Multivariate analyses of the level of parental monitoring (presented as odds ratio with $95 \%$ confidence interval; reference category: no monitoring) on the consumption of each substance including consuming peers as covariate

\begin{tabular}{lllll}
\hline & \multicolumn{2}{l}{ Substances } & & \\
\cline { 2 - 5 } Level of parental monitoring $^{\mathrm{b}}$ & Tobacco & Alcohol & Cannabis & Ecstasy \\
\hline Level 1 & $0.90[0.69-1.17]$ & $0.61[0.45-0.81]^{\mathrm{a}}$ & $0.93[0.68-1.26]$ & $0.36[0.15-0.89]^{\mathrm{a}}$ \\
Level 2 & $0.55[0.44-0.69]^{\mathrm{a}}$ & $0.64[0.50-0.82]^{\mathrm{a}}$ & $0.65[0.49-0.85]^{\mathrm{a}}$ & $0.47[0.22-1.01]$ \\
Level 3 & $0.54[0.43-0.69]^{\mathrm{a}}$ & $0.51[0.40-0.67]^{\mathrm{a}}$ & $0.53[0.40-0.71]^{\mathrm{a}}$ & $0.32[0.13-0.75]^{\mathrm{a}}$ \\
Level 4 & $0.43[0.35-0.55]^{\mathrm{a}}$ & $0.35[0.27-0.46]^{\mathrm{a}}$ & $0.37[0.28-0.49]^{\mathrm{a}}$ & $0.26[0.12-0.59]^{\mathrm{a}}$ \\
Consuming peers & $5.93[5.24-6.71]^{\mathrm{a}}$ & $4.60[3.98-5.32]^{\mathrm{a}}$ & $9.98[8.05-12.38]^{\mathrm{a}}$ & $95.89[49.90-184.24]^{\mathrm{a}}$ \\
\hline
\end{tabular}

${ }^{\text {a }}$ Statistically significant results

${ }^{\mathrm{b}}$ Controlled for age, gender, socioeconomic status, family structure, satisfactory relationship with mother, satisfactory relationship with father, satisfactory relationship with friends, and having substance consuming peers

seems to be a way for parents to significantly reduce the prevalence of substance use during adolescence.

Adolescence is a critical period for substance use with high levels of experimentation and initiation [5, 31, 33]. Through the mechanism of peer pressure and modeling, having consuming peers during adolescence greatly increases rates of substance use [12, 13, 26, 30]. As found partially by Wood et al. [32], Barnes et al. [3], and Marshall and Chassin [19] in their studies analyzing the influence of parents and peers on adolescent alcohol use, our results support that having or not having consuming peers has almost no influence on the protective effect of parental monitoring on substance use during adolescence. Actually, parental monitoring is important above and beyond the effects of peers, probably also because they have fewer consuming peers. Indeed, as there are relatively few differences between both multivariate analyses (Tables 3 and 4), our study indicates that the prevalence of adolescent substance use decreases even when adolescents have consuming peers and that the protective effect of parental monitoring seems to be strong enough to counterbalance the negative effect of peer pressure on adolescent substance use. Encouraging parents to improve their knowledge about with whom or where adolescents are in the evenings and to establish rules about what is allowed outside or inside the house are thus ways to limit the negative influence of consuming peers on adolescent substance use.

The main strength of our study is that it is based on a large nationally representative sample of Swiss adolescents. However, several limitations need to be stressed. First, the cross-sectional design of the analysis does not allow establishing causality, but the dose-dependent effect of our results seems to support the possibility of causality. Second, data were self-reported. However, the fact that the questionnaire was anonymous should minimize response bias. Finally, our scale had a relatively low alpha value $(0.62)$.
In conclusion, it seems necessary to remind parents that they can have an important role to play in the prevention of adolescent substance use. Parental monitoring is associated with decreased substance use and a lower association with consuming peers. As the prevention of substance use during adolescence is an essential way to improve their future, general practitioners and pediatricians need to encourage parents to set simple and clear rules for their children about what is allowed and what is not from an early age on and to know about their whereabouts and friends. Such an approach could have a protective effect on adolescent substance use.

Conflict of interest The authors declare that they have no conflict of interest.

\section{References}

1. Aseltine RH (1995) A reconsideration of parental and peer influences on adolescent deviance. J Health Soc Behav 36(2):103121

2. Bahr SJ, Hoffmann JP, Yang X (2005) Parental and peer influences on the risk of adolescent drug use. J Prim Prev 26(6):529-551

3. Barnes GM, Hoffman JH, Welte JW, Farrell MP, Dintcheff BA (2006) Effects of parental monitoring and peer deviance on substance use and delinquency. J Marriage Fam 68(4):10841104

4. Barnes GM, Reifman AS, Farrell MP, Dintcheff BA (2000) The effects of parenting on the development of adolescent alcohol misuse: a six-wave latent growth model. J Marriage Fam 62(1):175-186

5. Bauman A, Phongsavan P (1999) Epidemiology of substance use in adolescence: prevalence, trends, and policy implications. Drug Alcohol Depend 55(3):187-207

6. Baumrind D (1971) Current patterns of parental authority. Dev Psychol 4(1):1-103

7. Bogenschneider K, Wu MY, Raffaelli M, Tsay JC (1998) Parent influences on adolescent peer orientation and substance use: the interface of parenting practices and values. Child Dev 69(6):16721688 
8. Brook JS, Balka EB, Whiteman M (1999) The risks for late adolescence of early adolescent marijuana use. Am J Public Health 89(10):1549-1554

9. Chilcoat HD, Anthony JC (1996) Impact of parent monitoring on initiation of drug use through late childhood. J Am Acad Child Adolesc Psychiatry 35(1):91-100

10. Currie C (2008) Inequalities in young people's health: HBSC international report from the 2005/2006 survey. [Available from: http://public.eblib.com/EBLPublic/PublicView.do?ptiID=420994]. Accessed 4 May 2009

11. Dishion TJ, Nelson SE, Bullock BM (2004) Premature adolescent autonomy: parent disengagement and deviant peer process in the amplification of problem behaviour. J Adolesc 27(5):515-530

12. Dishion TJ, Owen LD (2002) A longitudinal analysis of friendships and substance use: bidirectional influence from adolescence to adulthood. Dev Psychol 38(4):480-491

13. Duncan SC, Duncan TE, Biglan A, Ary D (1998) Contributions of the social context to the development of adolescent substance use: a multivariate latent growth modeling approach. Drug Alcohol Depend 50(1):57-71

14. Galambos NL, Barker ET, Almeida DM (2003) Parents do matter: trajectories of change in externalizing and internalizing problems in early adolescence. Child Dev 74(2):578-594

15. Hoffmann JP, Su SS (1998) Parental substance use disorder, mediating variables and adolescent drug use: a non-recursive model. Addiction 93(9):1351-1364

16. Jessor R (1998) New perspectives on adolescent risk behavior. Cambridge University Press, New York

17. Kiesner J, Poulin F, Dishion TJ (2010) Adolescent substance use with friends: moderating and mediating effects of parental monitoring and peer activity contexts. Merrill-Palmer Q-J Dev Psychol 56(4):529-556

18. Kingree JB, Braithwaite R, Woodring T (2000) Unprotected sex as a function of alcohol and marijuana use among adolescent detainees. J Adolesc Health 27(3):179-185

19. Marshal MP, Chassin L (2000) Peer influence on adolescent alcohol use: the moderating role of parental support and discipline. Appl Dev Sci 4(2):80-88

20. Michaud PA, Berchtold A, Jeannin A, Chossis I, Suris JC (2006) Secular trends in legal and illegal substance use among 16-20- year-old adolescents in Switzerland. Swiss Med Wkly 136(1920):318-326

21. Miller TR, Levy DT, Cohen MA, Cox KL (2006) Costs of alcohol and drug-involved crime. Prev Sci 7(4):333-342

22. Mott JA, Crowe PA, Richardson J, Flay B (1999) After-school supervision and adolescent cigarette smoking: contributions of the setting and intensity of after-school self-care. J Behav Med 22(1):35-58

23. Ragin A (1999) The relationship between mental health and substance abuse among adolescents. US Dept. of Health and Human Services, Substance Abuse and Mental Health Services Administration, Office of Applied Studies, Rockville, MD

24. Rice DP (1999) Economic costs of substance abuse, 1995. Proc Assoc Am Physicians 111(2):119-125

25. Room R, Babor T, Rehm J (2005) Alcohol and public health. Lancet 365(9458):519-530

26. Simons-Morton B, Haynie DL, Crump AD, Eitel P, Saylor KE (2001) Peer and parent influences on smoking and drinking among early adolescents. Health Educ Behav 28(1):95-107

27. StataCorp (2007) Stata statistical software: release 10. College Station, TX: StataCorp LP

28. Stattin H, Kerr M (2000) Parental monitoring: a reinterpretation. Child Dev 71(4):1072-1085

29. Steinberg L, Fletcher A, Darling N (1994) Parental monitoring and peer influences on adolescent substance use. Pediatrics 93(6):1060-1064

30. Urberg KA, Degirmencioglu SM, Pilgrim C (1997) Close friend and group influence on adolescent cigarette smoking and alcohol use. Dev Psychol 33(5):834-844

31. Winters KC, Lee CS (2008) Likelihood of developing an alcohol and cannabis use disorder during youth: association with recent use and age. Drug Alcohol Depend 92(1-3):239-247

32. Wood MD, Read JP, Mitchell RE, Brand NH (2004) Do parents still matter? Parent and peer influences on alcohol involvement among recent high school graduates. Psychol Addict Behav 18(1): 19-30

33. Young SE, Corley RP, Stallings MC, Rhee SH, Crowley TJ, Hewitt JK (2002) Substance use, abuse, and dependence in adolescence: prevalence, symptom profiles, and correlates. Drug Alcohol Depend 68(3):309-322 